\title{
De witte jas ceremonie VUmc-compas: een middel tot bewustwording van professionaliteit?
}

\author{
N.M.M. Asselbergs-Brüll
}

\section{Samenvatting}

In 2005 is in het VU medisch centrum een nieuw curriculum geneeskunde volgens de bachelorl master structuur van start gegaan, genaamd 'VUmc-compas: competent en met compassie'. Op 25 oktober 2008 vond de eerste bachelordiploma-uitreiking plaats aan 160 studenten. Bij deze uitreiking werd een nieuwe ceremonie geintroduceerd naar Amerikaans model ('the White Coat Ceremony'). Deze ceremonie heeft tot doel de aankomende arts bewust te maken van zijn professionele functioneren. Dit artikel presenteert de achtergronden, intenties en praktische implicaties van de $V U$-versie van de 'witte jas ceremonie' (WJC) in het curriculum geneeskunde als middel tot reflectie over professioneel gedrag. Evaluatie van de ceremonie onder studenten liet zien dat $94 \%$ van alle respondenten (22\%) de WJC een waardevolle toevoeging vindt en deze zou aanbevelen aan andere faculteiten. (Asselbergs-Brüll NMM. De witte jas ceremonie VUmc-compas: een middel tot bewustwording van professionaliteit? Tijdschrift voor Medisch Onderwijs 2010(29)3:210-216.)

\section{Inleiding}

Geneeskunde studeren aan de VU betekent sinds 2005 het volgen van het nieuwe onderwijsprogramma 'VUmc-compas: competent en met compassie'. Een goede arts beschikt niet alleen over voldoende medische kennis, maar heeft ook het hart op de goede plaats, heeft oog voor de mens achter de ziekte en toont empathie. In het onderwijsprogramma VUmc-compas wordt aandacht besteed aan professioneel gedrag, conform de landelijke gerezen behoefte en gemaakte afspraken. Onder professioneel gedrag wordt observeerbaar gedrag verstaan waarin de normen en waarden van de beroepsuitoefening zichtbaar zijn. ${ }^{1-2}$ Reflecteren op gedrag wordt gezien als de basis van professionaliteit en de sleutel tot persoonlijke groei in dit gedrag. ${ }^{3}$ Het is echter moeilijk studenten in professioneel gedrag te onderwijzen, hen aan te zetten tot reflectie of dit proces objectiveerbaar te toetsen. ${ }^{4-5}$

Studenten leren professioneel gedrag deels in het reguliere curriculum: door werken in leergroepen, door communicatie- en reflectiepractica, door portfoliobesprekingen met de mentor, door rolmodellen, door patiëntencontacten en tot slot door toetsing van het gedrag tijdens leergroepen en stages. Daarnaast speelt een deel van het leren zich af buiten het zicht van de faculteit, in het 'hidden curriculum', tijdens discussies met familie en/of vrienden, peers en collega-artsen (bijvoorbeeld in de koffiekamer van een klinische afdeling). ${ }^{6}$

In het onderwijs in de bachelorfase kunnen we studenten voorbereiden op de grote stap die ze gaan maken, namelijk de transitie van de preklinische naar de klinische fase. Maar is men er werkelijk klaar voor? Is men voldoende doordrongen van de vele facetten die het arts zijn tot zo'n bijzonder vak maken, zoals de groeiende verantwoording, de continue beoordeling, de emotionele impact van een stervende medemens en het werken onder tijdsdruk? Diverse onderzoeken tonen aan dat deze transitiefase voor de aankomende arts een emotionele en stressvolle gebeurtenis kan zijn. $^{7-9}$ 
Arnold P. Gold, kinderneuroloog in Columbia (VS), dacht dat vroege bewustwording van studenten over hun toekomstige rol zou leiden tot een betere voorbereiding op de klinische fase. Het uitspreken van de eed van Hippocrates vond volgens hem te laat in de opleiding plaats. Volgens anderen was de eed bovendien aan vervanging toe. ${ }^{10}$ Om die reden ontwierp Gold in 1993 een ceremonie die plaatsvindt vóórdat de studenten de praktijk ingaan, de zogenaamde 'White Coat Ceremony' (WCC). Op dit moment vindt deze of een vergelijkbare ceremonie plaats in meer dan $90 \%$ van de medische faculteiten in de Verenigde Staten en sinds kort ook in Japan. Andere faculteiten als Tandheelkunde en Psychologie hebben vergelijkbare ceremonies gecreëerd. Er zijn diverse positieve ervaringen met het instellen van deze ceremonie. ${ }^{11-13}$

$\mathrm{Na}$ een presentatie van een White Coat Ceremony tijdens het congres van de 'International Association for Medical Education' besloot het VU medisch centrum (VUmc) de witte jas ceremonie (WJC) in te voeren als onderdeel van het traject professioneel gedrag. Het doel van deze interventie was de studenten, via het ontwerpen van een jaartekst, een middel te geven om over hun toekomstig professionele functioneren na te denken. Hieronder worden de praktische implicaties van deze interventie beschreven en worden in alle bescheidenheid enige positieve resultaten gegeven, inclusief de uitkomsten van een onder studenten verrichte evaluatie.

\section{Werkwijze witte jas ceremonie}

Het project kwam tot stand door een uniek samenwerkingsverband tussen het Instituut voor Onderwijs en Opleiden (IOO) en de Medische Faculteitsvereniging van het VUmc (MFVU). In het projectteam zaten de studieadviseurs, de PR-functionaris IOO, de examinator Professioneel Gedrag en assistente, een manager van het Onder- wijsbureau, alsmede de voorzitter en twee leden van de MFVU. Het projectteam kwam van februari tot en met oktober 2008 maandelijks bijeen en rapporteerde regelmatig aan de programmaleider van de bachelorfase VUmc-compas. Het projectteam had vooral een logistieke taak (draaiboek, uitnodigingen, diplomavoorbereidingen, begroting, receptie); de MFVU coördineerde de inbreng van de studenten.

Omdat ervoor gekozen was de WJC tegelijk te laten verlopen met de uitreiking van het bachelordiploma, was er ook overleg met de Examencommissie. De organisatie van de diploma-uitreiking wordt hier echter verder buiten beschouwing gelaten.

\section{Witte jas ceremonie}

De ceremonie omvatte: ${ }^{11}$

1. Een inleidende presentatie van een gastspreker waarin een humanistisch of ethisch geneeskundig aspect uiteengezet werd.

2. Het verwelkomen van de studenten als toekomstige collega's in de klinische fase via het aanreiken van een witte jas - het symbool van arts zijn - door een aantal docenten (de 'jasuitreikers').

3. Het voordragen van een door de studenten als jaargroep gemaakte jaartekst ten overstaan van familie, vrienden, faculteitsmedewerkers en medische staf.

4. Een feestelijke receptie.

ad. 1: De studenten bepaalden wie de gastspreker zou zijn via een voorkeurslijst op het digitale communicatiesysteem BlackBoard. Tijdens de ceremonie waren er diverse toespraken door respectievelijk de decaan, de programmaleider bachelorfase en door de door de studenten gekozen gastspreker.

ad. 2: De studenten gaven via BlackBoard aan door welke docenten/rolmodellen zij de witte jas uitgereikt wilden krijgen. Tijdens 
de ceremonie werden de studenten in achttallen op het podium geroepen. Daar ondertekenden ze hun diploma, ontvingen ze de officiële jaartekst en kregen ze vervolgens hun witte jas aangereikt door de gekozen docenten. Op deze wijze ontvingen ruim 160 studenten een witte jas als symbool voor hun toekomstige functie. Ter vergroting van de symbolische waarde kreeg de allereerste student zijn jas uitgereikt door de programmaleider van de masterfase.

ad 3: Met de jaartekst beschreven de studenten hoe zij zelf als coassistent wilden gaan functioneren, welke verantwoordelijkheden, idealen en verplichtingen zij verbonden zagen aan hun beroep en hoe zij deze wensten uit te dragen. De tekst fungeerde als een intentieverklaring. De kracht van de tekst zat juist hierin dat de woorden door de studenten zelf waren geformuleerd en de tekst niet was opgelegd door een standaardeed of door de faculteit.
Om tot deze jaartekst te komen discussieerden de studenten over alle competenties van het arts zijn. De coördinatie rond de jaartekst was in handen van de MFVU. Het maken van de tekst vergde van de studenten een goede samenwerking, organisatie en communicatie. Alle derdejaars studenten $(n=350)$ konden hun mening over de tekst kenbaar maken. Aangezien er een structuur was van leergroepen bestaande uit 12 studenten werd er per leergroep één contactpersoon benoemd. De kerngroep die zo ontstond vergaderde regelmatig in wisselende samenstelling van ongeveer 15 personen per keer en formuleerde de uiteindelijke tekst. Via BlackBoard vond uitwisseling en discussie met de jaargroep plaats. Om tot de tekst te komen vond er niet alleen onderlinge discussie plaats, maar werden ook coassistenten en een medisch specialist geïnterviewd over hun werkzaamheden.

De studenten bepaalden zelf hoe zij de jaartekst tijdens de ceremonie presenteerden.

Box 1. $1^{e}$ Jaartekst geneeskunde VU medisch centrum.

Wij, de studenten uit het eerste bachelorcohort, zijn allemaal verschillend, maar willen hetzelfde

Wij zullen ons laten leiden door nieuwsgierigheid en leergierigheid

Wij zullen uitdagingen aangaan en onze grenzen leren kennen

Wij zullen initiatief nemen en om hulp vragen wanneer dat nodig is

Wij zullen fouten erkennen en ervan leren

Wij zullen de grenzen van onze bevoegdheden handhaven

Wij zullen samenwerken en elkaar ondersteunen

Wij zullen respectvol omgaan met collega's en patiënten

Wij zullen de patiënt met professionele afstand en empathie tegemoet treden

Wij zullen leren van de patiënt

Wij zullen zoveel als mogelijk bijdragen aan de zorg voor de patiënt

Wij zullen wetenschappelijk onderzoek integreren in ons werk

Wij zullen als masterstudenten blijven meewerken aan de verbetering van het VUmc-compas

Wij zullen handelen naar ons geweten, daar waar geen richtlijnen zijn

Wij zullen de medische stand met waardigheid vertegenwoordigen

Wij zijn allemaal verschillend, maar willen hetzelfde: een goede dokter worden

Wij hebben er zin in! 
Zij kwamen gezamenlijk op het podium na ontvangst van hun diploma en witte jas. Bij deze eerste WJC kozen de studenten voor het uitspreken van één regel tekst per student met een gezamenlijk slotakkoord (regel 17; zie Box 1). Dit deden zij voor ruim 900 genodigden, in aanwezigheid van regionale en landelijke pers.

ad 4. De aard van het vermaak tijdens de receptie en de ceremonie (cabaret, muziek, artiest) werd bepaald door het projectteam.

\section{Evaluatie witte jas ceremonie}

Drie maanden na afloop van de WJC is een kleine enquête afgenomen. Naast organisatorische informatie wilden we ook door middel van zelfrapportage weten of de ceremonie daadwerkelijk leidde tot meer reflectie over professioneel gedrag. Naast algemene achtergrondinformatie werden er vragen gesteld als: het maken van een jaartekst heeft mij gestimuleerd na te denken over het professionele functioneren van een arts in het algemeen; de jaartekst is representatief voor mijn eigen verwachtingen en voornemens tijdens de coschappen; ik heb over de jaartekst en witte jas ceremonie gesproken met.....; de witte jas ceremonie tijdens de bachelordiploma-uitreiking is een waardevolle toevoeging aan het VUmccompas.
Tevens werd getracht te achterhalen of er een verschil was in beleving ten aanzien van de WJC voor mannen/vrouwen, ook in relatie tot de toekomstige beroepskeuze (zie Tabel 1 en 2).

\section{Resultaten evaluatie witte jas ceremonie}

De eerste bachelordiploma-uitreiking en WJC vond plaats op 25 oktober 2008 en was een bijzondere dag voor zowel studenten, docenten, medische staf als familieleden. De feestelijke uitreiking van de witte jassen en diploma's en het voorgedragen worden van de jaartekst werden met enthousiasme ontvangen. Na afloop waren er diverse mondelinge en schriftelijke positieve reacties van aanwezigen ten aanzien van deze nieuwe ceremonie. Het was duidelijk voor de aanwezigen dat de studenten trots waren op hun prestatie, maar ook de jasuitreikers waren trots dat zij verkozen waren tot rolmodel voor en door de studenten. 'Good vibes' alom.

Van de 160 studenten hebben er 36 de enquête geretourneerd (22\%). Hiervan is 28 vrouw $(78 \%)$ en 8 man $(22 \%)$, analoog aan de feitelijke verhoudingen in de jaargroep. Van de respondenten gaf slechts $22 \%$ aan dat de jaartekst tot reflectie aanzet. Van deze groep was driekwart actief in de MFVU, Studentenraad of in de Jaar

Tabel 1. Verschil in beleving witte jas ceremonie door mannen en vrouwen.

\begin{tabular}{|c|c|c|c|c|c|c|}
\hline & \multicolumn{3}{|c|}{ Mannen $(n=8)$} & \multicolumn{3}{|c|}{ Vrouwen $(n=28)$} \\
\hline & Ja & Nee & $?$ & Ja & Nee & $?$ \\
\hline Jaartekst representatief & $50 \%$ & $37,5 \%$ & $12,5 \%$ & $64 \%$ & $18 \%$ & $18 \%$ \\
\hline Voelt zich verwelkomt & $75 \%$ & $12,5 \%$ & $12,5 \%$ & $82 \%$ & $14 \%$ & $4 \%$ \\
\hline Gastsprekers* & $40 \%$ & $0 \%$ & $60 \%$ & $44 \%$ & $48 \%$ & $8 \%$ \\
\hline Cabaret* & $100 \%$ & & & $60 \%$ & $24 \%$ & $16 \%$ \\
\hline Ceremoniemeester* & $100 \%$ & & & $96 \%$ & $4 \%$ & \\
\hline Jaartekst uitspreken kon ik waarderen* & $100 \%$ & & & $68 \%$ & $24 \%$ & $8 \%$ \\
\hline WJC aanbevelen/waardevolle toevoeging & $100 \%$ & & & $93 \%$ & & \\
\hline
\end{tabular}

${ }^{*} n=5$ respectievelijk $n=25$ 
Tabel 2. Verschil in beleving witte jas ceremonie in relatie tot beroepskeuze voor huisarts/medisch specialist.

\begin{tabular}{lccccccc}
\hline & \multicolumn{3}{c}{ Huisarts $(\mathbf{n}=\mathbf{7})$} & \multicolumn{4}{c}{ Specialist $(\mathbf{n}=\mathbf{2 0})$} \\
\hline & Ja & Nee & $?$ & Ja & Nee & $?$ \\
Jaartekst representatief & $71 \%$ & $14 \%$ & $15 \%$ & $55 \%$ & $25 \%$ & $20 \%$ \\
Voelt zich verwelkomt & $71 \%$ & $29 \%$ & & $80 \%$ & $10 \%$ & $10 \%$ \\
Gastsprekers* & $43 \%$ & $43 \%$ & $14 \%$ & $40 \%$ & $40 \%$ & $20 \%$ \\
Cabaret* & $71 \%$ & $14 \%$ & $15 \%$ & $67 \%$ & $27 \%$ & $6 \%$ \\
Ceremoniemeester* & $100 \%$ & & & $100 \%$ & & \\
Jaartekst uitspreken kon ik waarderen* & $86 \%$ & $14 \%$ & & $60 \%$ & $27 \%$ & $13 \%$ \\
WJC aanbevelen / waardevolle toevoeging & $100 \%$ & & & $95 \%$ & \multicolumn{2}{c}{$5 \%$} \\
\hline
\end{tabular}

${ }^{*} \mathrm{n}=7$ respectievelijk $\mathrm{n}=15$

Vertegenwoordigingscommissie. Om ook een indruk te krijgen van reflectie binnen het 'hidden curriculum' is gevraagd met wie zij de jaartekst besproken hebben: 97\% heeft over de jaartekst gesproken met medestudenten, 64\% met vrienden, $67 \%$ met familie.

Opvallend is dat ondanks het feit dat 20-22\% de jaartekst niet representatief vond of het uitspreken ervan niet kon waarderen, toch $94 \%$ van alle respondenten de WJC een waardevolle toevoeging vond en deze zou aanbevelen aan andere faculteiten.

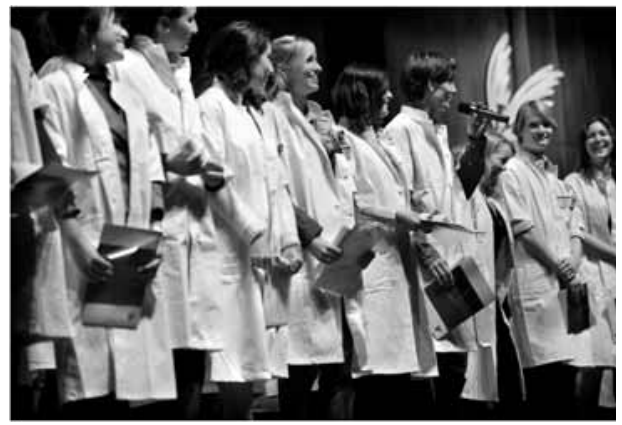

Het uitspreken van de jaartekst (Foto: DigiDaan).

\section{Beschouwing}

Onze aanpak verschilt in een aantal opzichten van de Amerikaanse White Coat Ceremony. In Amerika vindt de WCC plaats na een aantal weken onderwijs in jaar 1 van de bacheloropleiding. Wij kozen ervoor de ceremonie te laten plaatsvinden tijdens de bachelordiploma-uitreiking, dus na het derde studiejaar. Voor de studenten is dit een belangrijk moment omdat men hierna de overstap maakt naar de klinische fase van de masteropleiding. Juist op dit punt is volgens ons bewustwording van de verplichtingen en verantwoordelijkheden van een student als toekomstig arts cruciaal.

Ook hadden de studenten in onze ceremonie meer de regie doordat zij zelf hun voorkeur voor een gastspreker en entertainment konden aangeven. Bovendien moesten de studenten kenbaar maken door welke docenten/medisch specialisten zij de jas uitgereikt wilden krijgen. Daarmee werden door hen duidelijke rolmodellen aangegeven. Deze regiekeuze dwong hen in onze ogen wederom tot reflectie en vergrootte hun betrokkenheid bij de ceremonie.

Voor het projectteam was de jaartekst het belangrijkste onderdeel van de ceremonie. Immers, onze stelling was dat discussie over de jaartekst tot meer inzicht in en bewustwording van professionaliteit en professioneel gedrag zou leiden. Maar is de jaartekst nu daadwerkelijk een middel om tot meer persoonlijke reflectie te komen omtrent professioneel gedrag? Het antwoord ligt 
genuanceerd. De respons op de enquête was laag (mede door het feit dat een groot aantal studenten in de wachttijd voor hun masterfase in het buitenland verbleef) waardoor wij de resultaten met voorzichtigheid moeten bezien. Slechts $22 \%$ van de respondenten gaf aan dat de jaartekst tot reflectie aanzette. Meer vrouwen (64\%) dan mannen $(50 \%)$ vonden de jaartekst representatief. Van de mannen kon echter $100 \%$ het uitspreken van de tekst waarderen ten opzichte van $68 \%$ van de vrouwen. Wij beseffen echter dat deze getallen te klein zijn om duidelijke conclusies te trekken.

Volgens de enquête én naar de mening van de kerngroep van de MFVU is de jaartekst toch vooral het product van deze kleine groep. De door ons gewenste reflectie vond echter wel plaats binnen deze kerngroep hetgeen bevestigd werd door beeldmateriaal. Onder leiding van documentairemaakster Nina Pieters zijn namelijk filmopnames gemaakt van de reflectiegesprekken van de kerngroep, als onderdeel van een documentaire over de WJC.

Aan ons de uitdaging om bij een volgende ceremonie de betrokkenheid van de jaargroep te vergroten en aldus de reflectiekracht van deze interventie te versterken. Een optie is de voorbereidingen voor de jaartekst niet facultatief te laten plaatsvinden, maar een plek te geven in het reguliere curriculum in practica of colleges over professioneel gedrag en de WJC. Daarnaast is de vraag wat het effect van een eenmalige interventie op de lange termijn is voor het reflecteren over professioneel gedrag. Studies laten zien dat reflecteren een continuüm is en men moet blijven oefenen om de kunst meester te worden..$^{3-4}$ Een verbetering kan zijn het toevoegen van terugkoppelingsmomenten met betrekking tot de jaartekst, bijvoorbeeld tijdens de terugkomdagen in de masterfase of tijdens het bespreken van het porfolio met de student.
Tot slot: er zijn ook kritische geluiden. De jas zou teveel een symbool zijn van de hiërarchische, arrogante medische stand en juist tot grotere distantie en uitzonderingspositie van de jonge arts leiden. De ceremonie zou niet de zorg voor de patiënt vooropstellen ('caring'), maar juist het autoritaire gevoel op basis van uniform en titel versterken. ${ }^{14}$ Deze mening delen wij echter niet, getuige ook de vele positieve reacties van studenten en hun ouders na afloop van de ceremonie.

Een ander tegengeluid is dat een eed niet zinvol is omdat de studenten de inhoud ervan door gebrek aan ervaring nog niet kunnen bevatten, en dat het uitspreken van een eed geen enkele betekenis heeft voor het individu wanneer het een groep min of meer is opgelegd. ${ }^{15}$ Volgens de door ons gehanteerde werkwijze is de jaartekst echter niet door de faculteit opgelegd en wordt zij gemaakt voor en door studenten. Er is voldoende inspraak mogelijk, alleen de betrokkenheid is wel een punt van aandacht. Als de betrokkenheid niet groter wordt, dan is de tekst in zekere zin toch opgelegd. In dit geval niet door de faculteit, maar door een kleine groep studenten die de tekst bepaalt voor de gehele jaargroep.

\section{Conclusie}

Met deze WJC is een aanzet gegeven tot een interventie voor professioneel gedrag welke nog verder uitgewerkt dient te worden in de komende jaren. VUmc gaat deze groep masterstudenten volgen op hun pad. Aan ons als opleiders de taak hen goed te begeleiden en te weerhouden van cynisme of vervaging van humanistische waarden. Daarnaast willen wij inventariseren of onze verwachtingen ten aanzien van dit bewustwordingsmiddel correct zijn. Wij hopen dat de onderlinge discussie die de jaartekst heeft gevormd ook helpt om tijdens het werk als coassistent over de genoemde waarden te blijven praten met 
medische en paramedische collega's. Zo blijft de arts werkelijk 'competent en met compassie'.

\section{Dankwoord}

Met dank aan Victor van Bochove, masterstudent jaar 1 VUmc-compas, voor zijn heldere en vlotte verwerking van de enquêteformulieren.

\section{Literatuur}

1. Rynja $\mathrm{S}$ et al. Tabee lomperiken en horken. Med Contact 2007(2):73-5. [Bye Bye louts and boors. Medical Contact 2007(2):73-5].

2. Professioneel gedrag: onderwijs, toetsing, begeleiding en regelgeving. Projectteam Consilium Abeundi; 2002. [Professional behaviour: teaching, testing, guidance en regulation. Project team Consilium Abeundi; 2002].

3. Aukes L.C. Personal reflection in medical education (dissertatie). UMCG 2008.

4. Boenink A.D. Teaching and learning reflection on medical professionalism (dissertatie). VUmc 2006.

5. Dekker H. Onderwijs in professionaliteit. Med Contact 2009; 64:466-9. [Professionalism education. Medical Contact 2009;64:4666-9].

6. Stern DT. In search of the informal curriculum. Acad Med 1998;73:S28-30.

7. Prince KM, van de Wiel et al. A qualitative analysis of the transition from theory to practice in undergraduate training in a PBL-medical school. Ad Health Sci Educ 5(2):105-116.
8. Van Hell EA. et al. Transition to clinical training: influence of preclinical knowledge and skills, and consequenses for clinical performance. Med Educ 2008;42:830-837.

9. Radcliffe C, Lester H. Perceived stress during undergraduate medical training: a qualitative study. Med Educ 2003;37:32-8.

10. Hurwitz B, Richardson R. Swearing to care: the resurgence in medical oaths. BMJ 1997;315:16714.

11. Gillon R. White coat ceremonies for new medical students. J Med Ethics 2000 Apr; 26(2):83-84.

12. Huber SJ. The white coat ceremony: a contemporary medical ritual. J Med Ethics $2003 \mathrm{Dec}$; 29(6):364-6.

13. Sritharan K. Medical oaths and declarations. BMJ 2001 Dec;323(7327):1440-1.

14. Russel PC. The White Coat Ceremony: turning trust intro entitlement. Teach Learn Med 2002 Winter; 14 (1);56-9.

15. Veath RM. White coat ceremonies: a second opinion. J Med Ethics 2002 Febr;28(1):5-6.

\section{De auteur:}

Mw. drs. N.M.M. Asselbergs-Brüll is oogarts en examinator Professioneel Gedrag in het VUmc te Amsterdam.

Correspondentieadres:

Drs. N.M.M. Asselbergs-Brüll, Vumc, afdeling Oogheelkunde, postbus 7075, 1007 MB Amsterdam; e-mail: n.asselbergsbrull@vumc.nl

Belangenconflict: geen

Financiële ondersteuning: Sponsoring werd verkregen van de Stichting VU-Windesheim, VVAA, Gold Foundation en Raad van Bestuur VUmc

\section{Summary}

In 2005 the VU Medical Centre (VUmc) Amsterdam implemented a new medical curriculum according to the bachelormaster structure, called VUmc-compass: competent and compassionate. On October 25th 2008 the first 160 students received their bachelor's degrees in a ceremony modelled on the US White Coat Ceremony. The purpose of this ceremony is to heighten junior doctors' awareness of their role as professional. We describe the background and considerations that have led to the VUmc version of the white coat ceremony as a tool to promote reflection on professional behaviour. We also address some practical implications around the organisation of the ceremony.

A first evaluation of the ceremony among 160 students (response 22\%) shows that $94 \%$ of respondents think the ceremony has added value and would recommend it to other medical schools. (Asselbergs-Brüll NMM. VUmc compass 2008: a white coat ceremony to enhance awareness of professionalism? Netherlands Journal of Medical Education 2010(29)3:210-216.) 